\title{
Modal Analysis on Working Equipment of Hydraulic Excavator
}

\author{
Caiyuan Xiao ${ }^{1}$ and Zhang Guiju ${ }^{*}, 1,2$ \\ ${ }^{I}$ Department of Mechanical and Energy Engineering, Shaoyang University, Shaoyang 422004, China \\ ${ }^{2}$ College of Mechanical and Electrical Engineering, Central South University, Changsha, 410083, China
}

\begin{abstract}
In the traditional design of the working equipment of the hydraulic excavator, its stress distribution was almost determined by adopting the static calculation method, and then its strength was ensured by selecting the safety factor, which is not fully considered because of the dynamic stresses resulting from shocks and vibrations in the operating process of the hydraulic excavator. Based on the finite element analysis software ANSYS, the 3D models of the main components (boom and bucket rod) of the working equipment for certain type of hydraulic excavator were analyzed. The inherent frequency and the main vibration mode were analyzed by extracting the first 6-th order modal. The research results show that with the increase of modal order, the vibrating mode form increased in complexity. The first and the second orders vibrating mode can be both a linear bending deformation or muster within a certain plane individually. From the beginning of the third order, the model deflection begins to become a mutual coupling complex vibrating type which showed multiple orders of bending and torsion deformation. The maximum deflection of boom is concentrated near the ear plate as well as the hinge point connected with boom and oil cylinder. On the other sides, the maximum deflection of bucket rod is concentrated on its middle part. i.e. between the hinge joints of rocker and the ear plate as well as near the rear supporting plate. Therefore, in order to ensure strength and working safety of the working equipment, it is necessary to improve the structure of the maximum deformation. The Modal analysis provides important modal parameters for the corresponding analysis of the boom and bucket rod of the working equipment in hydraulic excavator, and provides a basis for the optimization design of the analysis on total vibration and structural dynamic characteristics.
\end{abstract}

Keywords: Boom, bucket rod, excavator, modal analysis.

\section{INTRODUCTION}

Hydraulic Excavator is industrial machinery, used for mining and excavations. It is experiences immense vibrations and stress/strain loads in operation. Studies have shown that the vibrations of the excavator are the effect of external loads. Meanwhile, it is related to the dynamic characteristics of the working equipment and the vibration characteristics when locking the hydraulic cylinder. In the traditional design for working equipment of hydraulic excavator, its stress distribution was almost determined by adopting the static calculation method, and then its strength was ensured by selecting the safety factor. This method does not guarantee the dynamic characteristics to meet the needs of the working equipment. Therefore, in order to scientifically design the structure of the working equipment and to improve its service life it is necessary to research the dynamic characteristics of the working equipment. Tadeusz Smolnicki et al [1] mounted sensors on excavator's boom to determine the static and dynamic load for structural strain characteristics through testing the data. Furthermore, they also developed a fatigue detection system of hydraulic excavator to control the risk caused by the fatigue crack. G. wszolek [2] wrote the GRAFSIM programs by using the SIMULINK simulation module from MATLAB software, which analyzed the vibrational characteristics of the excavator's virtual prototype under applied excitation. Liu Benxue [3] analyzed the movement and loading of the excavator's working equipment by using the method of D-H and received the working trajectory of bucket with the computer language $\mathrm{C}$. According to the characters of the excavator's working equipment, the model, static and transient dynamic analysis were conducted by using ANSYS software, and finally the causes for the occurrence cracks for a certain type of excavator's working equipment are discovered. Pan Yu'an [4] established the ADAMS simulation model of virtual prototype of the backhoe excavator's working equipment. Based on the virtual prototype technology and the general reduced gradient method, with the assumption that the working stress of the bucket, the bucket rod and the boom cylinder were minimum, the simulation optimized the design of the structure of the bucket, the bucket rod and the boom cylinder. In the research of the key designing technology for the working equipment of the hydraulic excavator, Du Wenjing [5] put forward an integrated finite element analysis on the working equipment and introduced the FEM for the contact analysis which was then successfully analyzed. Based on the FEA software ANSYS, the 3D models of the main components (boom and bucket rod) of the working equipment for a certain type of hydraulic excavator were, pre-stress modal, analyzed, for obtaining the inherent frequency and the modal vibration mode of boom and bucket rod under four different kinds of working conditions. 
Compared to the excavator's working frequency, the natural frequencies and the vibration modes are analyzed, which provided important modal parameters to the corresponding analysis for excavator's boom and bucker rod as well as a basis for the optimization design for the analysis on total vibration and structural dynamic characteristics.

\section{MODAL ANALYSIS THEORY}

Modal analysis is used to determine the vibration characteristics of the design mechanism of the machine components, namely the structure's inherent frequency and vibration mode which are important parameters of the structural design under the dynamic load. At the same time, it can also be used as the starting point of other dynamic analysis problems, such as the transient dynamic analysis, the harmonic response analysis and the spectral analysis. If the inherent frequency of a certain structure is known, the inherent frequency of the structure can avoid the use of external excitation frequency in the process of design and improvement, thus avoiding resonance and deformation.

Under any damping, the response of each point on the external force in the mechanical structure can be expressed as the superposition of the vibration mode from different orders which consisted of some modal parameters such as inherent frequency, damping ratio and vibration mode and so on. The general equation of the motion is [6].

$$
[M]\{\ddot{\mu}\}+[C]\{\mu\}+[K]=\{F(t)\}
$$

where, $[M]$ is the mass matrix of structure; $[C]$ is the damping matrix of structure; $[K]$ is the stiffness matrix of structure; $\{\mu\}$ is the displacement matrix of structure; $\{F(t)\}$ is the vector of the exciting force.

The assumptions and constraints of the modal analysis are stiffness and mass of the structure, and the quality must remain constant. Furthermore, the structure is not affected by the change of force, displacement, pressure and temperature. According to the assumptions and limitations stated above, the equation of motion for an un-damped system (free vibration) can be written as

$[M]\{\ddot{\mu}\}+[K]\{\mu\}=\{0\}$

For linear systems, Eq. (2) has the following simple harmonic form

$\{\mu\}=\{\phi\}_{i} \cos \omega_{i} t$

where, $\{\phi\}_{i}$ is the vibration mode function of the $i$-th order inherent frequency; $\omega_{i}$ is the $i$-th order natural angular frequency; $t$ is the time.

Then Eq. (2) can be transformed into

$\left(-\omega_{i}^{2}[M]+[K]\right)\left\{\phi_{i}\right\}=\{0\}$

To make the Eq. (4) sure, there are two possible ways: $\{\phi\}_{i}=\{0\} \quad$ or $-\omega_{i}^{2}[M]+[K]=\{0\}$. The former is obviously not significant for the solution, so
$\left|[K]-\omega_{i}^{2}[M]\right|=0$

Eq. (5) is called the characteristic equation of the system, and it boils down to solve the eigenvalue problem. Then the $n$ values of $\omega^{2}$ and $n$ feature vectors can be found to the satisfaction of Eq. (5), where $n$ is the number of degrees of freedom. Therefore the $n$ order inherent frequency is the required output.

Assumed $\lambda=\omega^{2}$, the expression of $n$ feature values $\lambda_{i}$ can be written as

$\left|-\lambda^{2}[M]+[K]\right|=0$

where, $[M]$ is the mass matrix, namely the general matrix of all meshing elements; $[K]$ is the stiffness matrix, namely the general stiffness matrix of all the meshing elements. The socalled stiffness establishes the ratio of the force (torque) increment and the generated displacement (angle) increment of the elastic body.

When outputting, we are concerned with the object's natural frequency rather than its inherent frequency. The relation between natural frequency and circular frequency can be obtained through the conversing formula, so the $i$ order inherent frequency is

$f_{i}=\frac{\omega_{i}}{2 \pi}$

The inherent frequency $f_{i}$ and the modal have an important significance in the vibrational analysis, and they are all determined by the stiffness matrix $[K]$ and the mass matrix $[M]$ of the system.

\section{MODELING AND MESHING}

\subsection{Finite Element Modeling}

For he modal analysis of the work equipment in the hydraulic excavator a 3D model needs to be constructed. Therefore, in this paper, the professional three-dimensional modeling software UG (Unigraphics NX) is chosed to model the working equipment and then the model is imported into ANSYS software for further analysis. In the modelling process, some simplifying assumptions and hypothesis must be defined as follows: (a) The boom material is assumed to be uniform, continuous as well as isotropic; (b) The errors caused by tolerance fit and machining error, etc. are ignored; (c) All dimensions of boom and bucket rod are modeled according to the basic size; (d) Because the components of boom are welded, the joints between various components are viewed as rigid connections. By the assumptions and hypothesis stated above, the modeling workload can be reduced and the computational efficiency can be improved, but it can also have a significant impact on the calculation results [7].

It is necessary to define the material properties after importing 3D models into ANSYS. The main material of working equipment usually is Q345 and some $16 \mathrm{Mn}$. 
(a) Boom

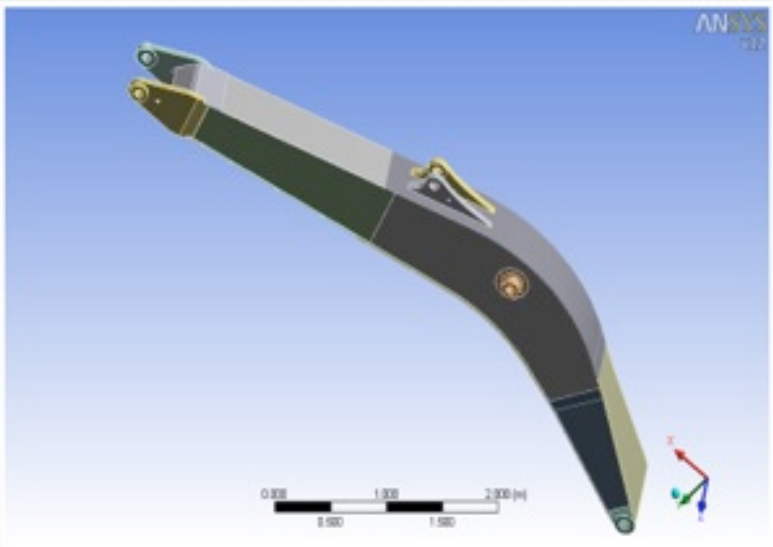

(b) Bucket rod

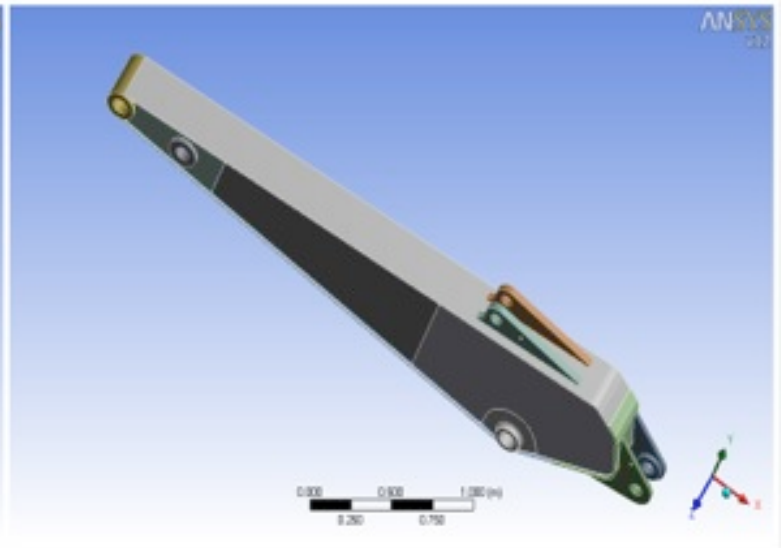

Fig. (1). 3D finite element model.

Material properties of Q345 are: density $\rho=7800 \mathrm{Kg} / \mathrm{m}^{3}$, elastic modulus $E=2.1 E+11 P a$, and Poisson's ratio $\mu=0.3$. Because $16 \mathrm{Mn}$ and Q345 have similar material properties, therefore, the material properties are defined by Q345 according to the ISO system. Construction of the three dimensional finite element model is shown in Fig. (1).

\subsection{Meshing}

For the meshing function in ANSYS, there are two kinds of meshing forms: the free mesh and the mapping mesh. The free mesh can automatically select different types of elements and densities to combine with each other according to the model shape. Hence, the element type generated by the free mesh form is more reasonable for the whole model in many cases [8]. Therefore, the free mesh method is chosen to mesh the model in this paper, and the mapping mesh method is chosen to adjust the model in some local areas. The meshing model is shown in Fig. (2).

\section{CONSTRAINT AND LOAD}

This research is to analyze the vibration mode of the boom and bucket rod under two practical operating

(a) Boom

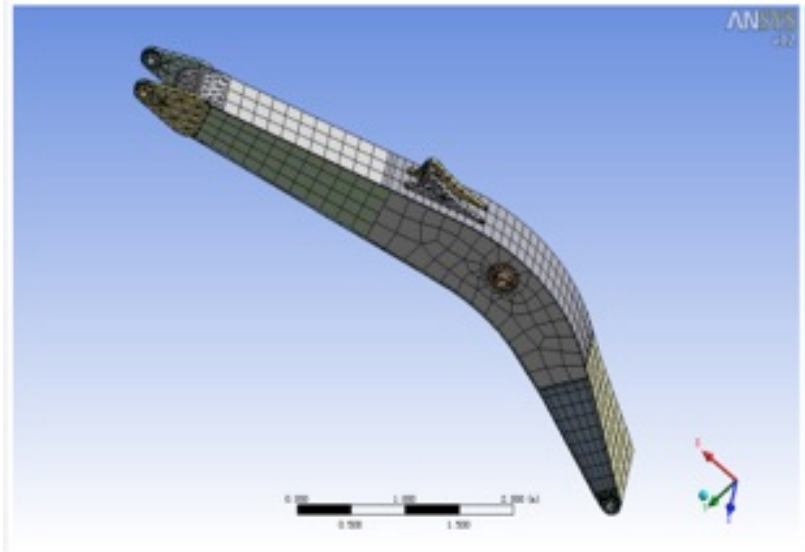

conditions. The pre-Stress Modal module chosen here firstly carries out the static analysis to apply the stress produced by loads (pre-stress) onto the model structure and then the modal is analyzed. In order to avoid the singularity of the total stiffness matrix, it must eliminate the displacement of rigid body model, which can constrain some nodes. The constraint condition is: the addition of constraints eliminates free displacement of all rigid bodies, or the constraint is changed to boundary element with stiffness large enough as supplementary measures to checking load balance. According to the boundary conditions, the constraints are applied separately, and imposed on the tail end connection The displacement along the direction of three axes $(X, Y, Z)$, the front of the model as well as the displacement along the direction of the two axes $(Y, Z)$.

\subsection{Constraint and Load of Boom}

The position to calculate the boom's strength should be chosen according to the maximum load which may appear in the mining work [9]. Boom condition I: The boom is at the lowest position (when boom cylinder is fully contracted), the three positions, the end of the bucket tooth, the hinge of the bucket and the bucket rod, and the hinge of the bucket rod and the boom are all located on the vertical line. Boom

(b) Bucket rod

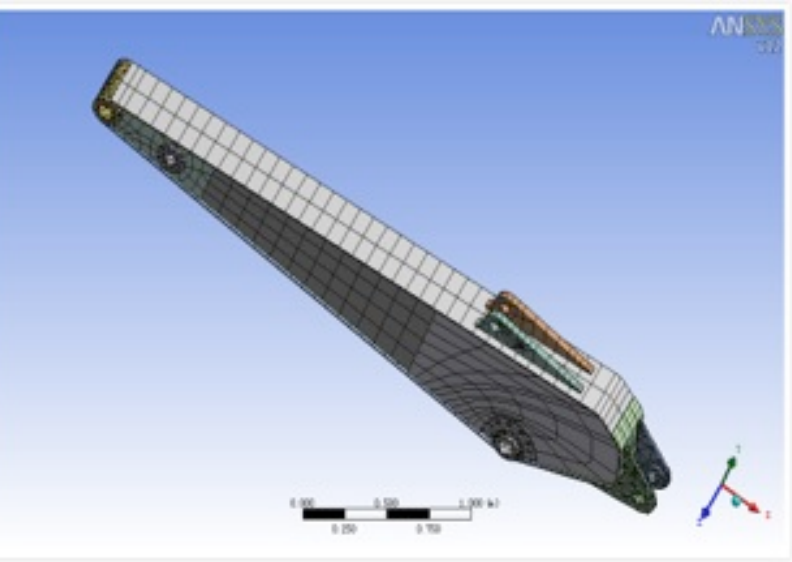

Fig. (2). Meshing mode. 
(a) Boom condition I

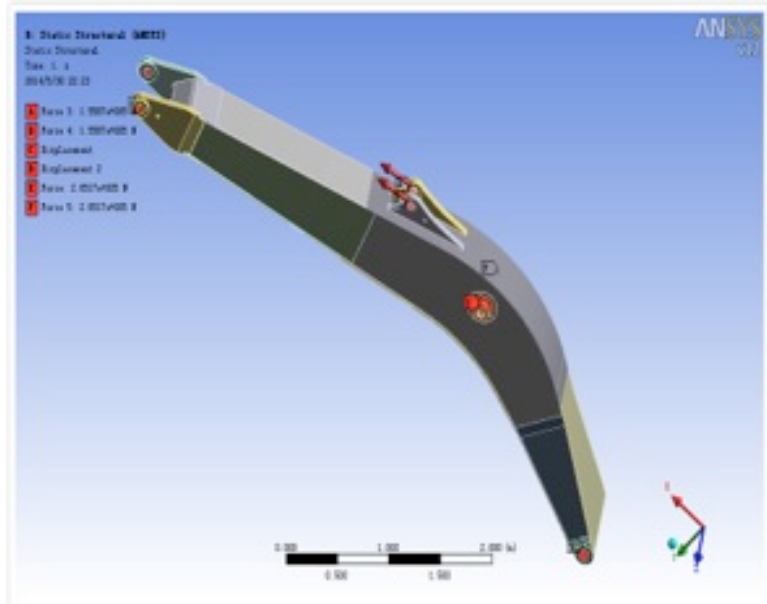

(b) Boom condition II

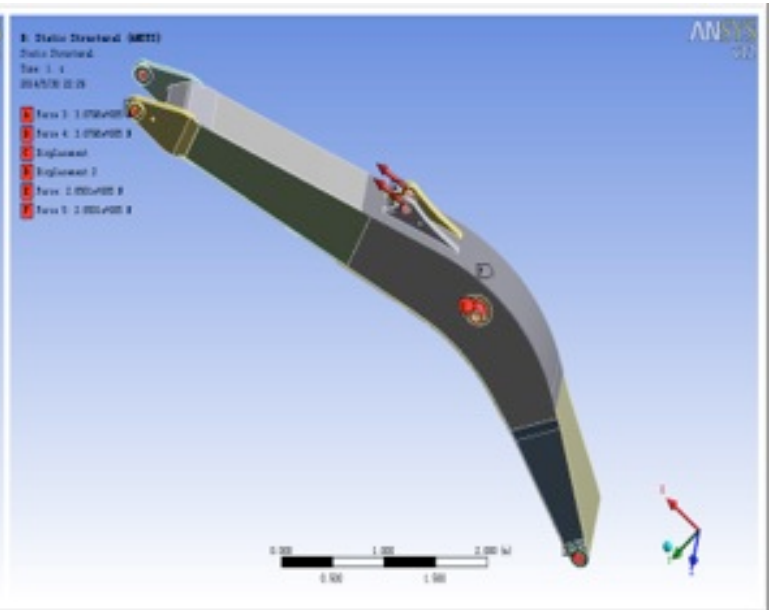

Fig. (3). Constraint and load of the boom.

condition II: The boom is at the position of maximum position with the boom cylinder fully extended, where the bucket rod is at the position of maximum arm of force for the bucket rod cylinder (whenand the angle between the bucket rod cylinder and the bucket rod end axis is 90 degrees). Constraint and load of the boom are as shown in Fig. (3).

\subsection{Constraint and Load of the Bucket Rod}

Strength of the bucket rod is mainly controlled by the moment, so its calculating position can be determined by the moment which may occur during digging resistance to the bucket rod [9]. Bucket rod condition I: The boom is at the lowest position (when boom cylinder is fully contracted), and the bucket rod is at the position of maximum arm of force for the bucket rod cylinder (when at angle between the bucket rod cylinder and the bucket rod end axis is at 90 degrees). The tooth tip of the bucket rod is positioned on the extension line of the joint line between the hinge of the bucket rod and the bucket rod and the hinge of the bucket rod and the boom, along with the lateral teeth obstacles. Bucket rod condition II: The boom is at the position of maximum arm of force for the boom cylinder, and the bucket rod is at the position of maximum arm of force for the bucket rod cylinder (when the angle between the bucket rod cylinder and the bucket rod end axis is at 90 degrees ). The tooth tip of the bucket rod is positioned on the extension line of the joint line between the hinge of the bucket rod and the bucket rod and the hinge of the bucket rod and the boom, along with digging resistance is symmetric to the bucket rod to mining. Constraint and load of bucket rod are as shown in Fig. (4).

\section{CALCULATING RESULTS AND ANALYSIS}

\subsection{Boom}

Because the low order inherent vibration type plays a decisive role on dynamic characteristics of the bucket rod structure, it can only analyze the first 6 orders of inherent frequencies and the corresponding vibration mode. Boom condition I and II for the first 6 orders of inherent frequencies and the vibration type description are as shown in Table 1. Vibration modes for boom of finite element analysis are as shown in the Fig. (5). (a) Bucket rod condition I

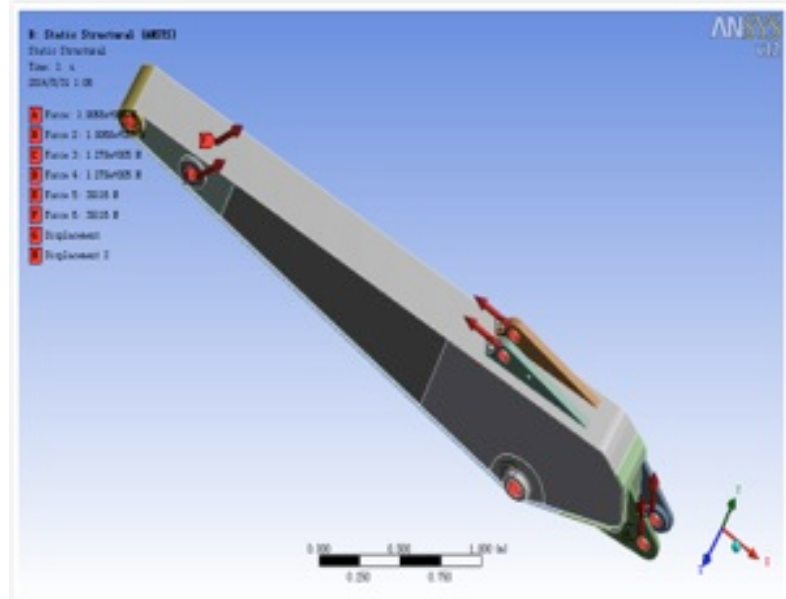

(b) Bucket rod condition II

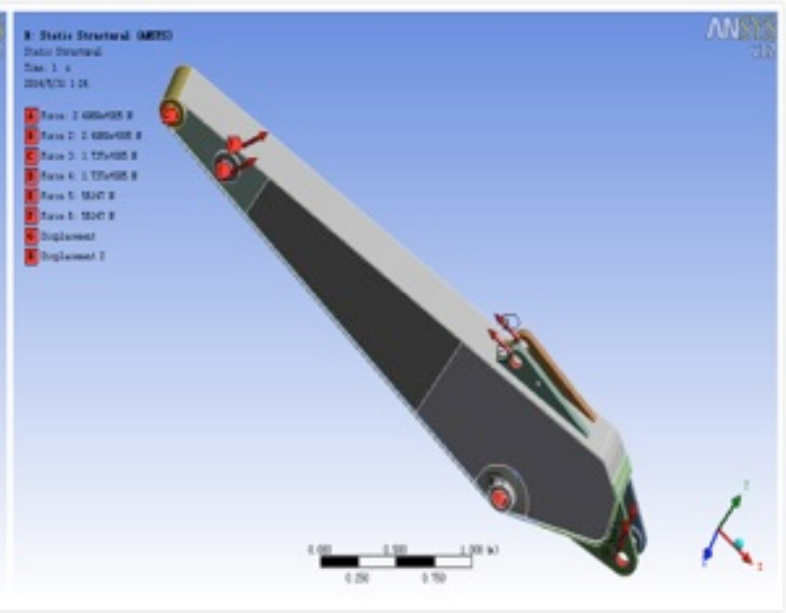

Fig. (4). Constraint and load of bucket rod. 
Table 1. Boom condition I and II for the first 6 orders of the inherent frequencies and the vibration mode description.

\begin{tabular}{|c|c|c|c|}
\hline Order & $\begin{array}{c}\text { Inherent } \\
\text { Frequency of } \\
\text { Boom } \\
\text { Condition } \mathbf{I} / \mathbf{H z}\end{array}$ & $\begin{array}{c}\text { Inherent } \\
\text { Frequency of } \\
\text { Boom } \\
\text { Condition II/Hz }\end{array}$ & Vibration Type Description \\
\hline \hline 1 & 48.09 & 48.14 & The $1^{\text {st }}$ order bending vibration on plane $\mathrm{X}, \mathrm{Z}$ \\
\hline 2 & 53.29 & 53.33 & The $1^{\text {st }}$ order bending vibration on plane $\mathrm{Y}, \mathrm{Z}$ \\
\hline 3 & 107.78 & 107.81 & The $2^{\text {nd }}$ order bending vibration on plane $\mathrm{X}, \mathrm{Z}$ and slightly muster at bending position \\
\hline 4 & 128.41 & 128.10 & The larger muster at the middle position of front supporting plate and ear plate \\
\hline 5 & 136.48 & 136.57 & The $3^{\text {rd }}$ order bending vibration on plane $\mathrm{Y}, \mathrm{Z}$ and muster at bending position \\
\hline 6 & 157.10 & 157.07 & The three continuous musters at the middle position of the hinge between front supporting plate and boom cylinder \\
\hline
\end{tabular}

It can be seen from Table 1 that the first 6 orders of the inherent frequencies of the boom structure are between 48 $\mathrm{Hz}$ and $158 \mathrm{~Hz}$. Both of the inherent frequencies and the vibration modes are basically the same under the conditions of I and II, and with increase of the modal order, the boom's performance of modal vibration mode also increased in complexity. From Fig. (5) it can be seen that the deformation continuity of each order of the vibration mode diagram are satisfactory without obvious mutation occurring, which proved a good integral rigidity of the boom.

At the same time, we can see that the $1^{\text {st }}$ and the $2^{\text {nd }}$ order modal modes only are a $1^{\text {st }}$ order bending deformation within a certain plane and the maximum deformation is nearly concentrated towards the hinge point of the rear plate and the boom cylinder. From the beginning of the $3^{\text {rd }}$ order, the model deformation begins as the complex vibration modes are coupled with bending and torsion deformation. Moreover, the inherent frequency of the $3^{\text {rd }}$ order modal grows larger than the $2^{\text {nd }}$ order. Therefore, it needs to control the maximum deformation of the $3^{\text {rd }}$ vibration modes. From the $3^{\text {rd }}$ order, the boom's maximum deformation begins to offset from its central section to the front section, which is largely concentrated in the front. Furthermore, between the front of the supporting plate and the rear plate, the deformation present in both side plates and top and bottom covers of the boom. Thus, this proves that the two positions may be the stress concentration points. Because speed of the excavator's engine is about 800 to $900 \mathrm{rpm}$, the frequency is about $15 \mathrm{~Hz}$, and the working frequency is about $35 \mathrm{~Hz}$, which is similar to the first order and the second order frequency. Therefore in order to ensure the boom strength and safety in operation, it is required to improve the structure of the hinge point near the rear plate and the boom cylinder and the front section of the boom, where we can appropriately increase the thickness of the boom cover or the rib.

\subsection{Bucket Rod}

The bucket rod conditions I and II for the first 6 orders of the inherent frequencies and the vibration type description are as shown in Table 2 . It can be seen that the inherent frequencies and the vibration modes of conditions I and II are basically in agreement. With the modal order increasing, the bucket rod's performance of the modal vibration mode increases in complexity. The vibration modes for the bucket rod of the FEA are as shown in the Fig. (6). It can be seen that the bucket rod has good integral rigidity. At the same time, the first and the second orders modal modes only are a $1^{\text {st }}$ order bending deformation within a certain plane and the bucket rod just deforms in the middle section. From the beginning of the $3^{\text {rd }}$ order, the model deformation performs the complex vibration modes with multiple orders coupled with torsion deformation. The maximum deformation distributes on the middle of the bucket rod, namely between the hinge point of the rocker and the rear plate as well as the back supporting plate. We must pay more attention to the maximum deformation and improve the unreasonable structure.

\section{CONCLUSION}

Through the analysis of the inherent frequencies and the vibration modes of the boom and the bucket rod, the following conclusions can be drawn:

(1) The first 6 orders of frequencies of the boom structure are $48 \mathrm{~Hz}$ to $158 \mathrm{~Hz}$ and the bucket rod structure are $132 \mathrm{~Hz}$ to $194 \mathrm{~Hz}$. Both the inherent frequencies of the boom and the bucket rod greatly change at the third modal with modal vibration mode fluctuation. From the third order modal, both structures perform more complex coupling vibrations. Therefore, it is necessary to strengthen the maximum deformation at the third modal.

(2) Both deformations of the boom and the bucket rod are transferred from a single direction to a multi direction. With the modal order increasing, structure's inherent frequency increases and the vibration modes also become more complex. The first two order modes of the boom and the arm are of simple single direction bending. But the vibration mode after the third order transforms into various combinations of vibrations deformation. At the same time, the degree of deformation is higher.

The boom's maximum deformation is at the middle position of the hinge point between the front plate and the boom cylinder, as well as near the hinge point between the rear plate and the boom cylinder. The maximum deformation distributes on the middle of the bucket rod, namely between the hinge point of the rocker and the rear plate as well as the nearly back supporting plate. Therefore, we must pay more 
(a)

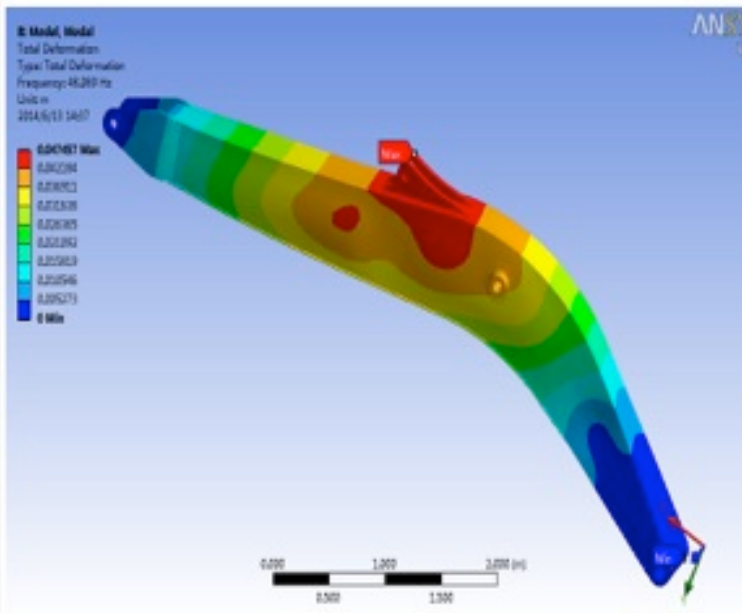

(c)

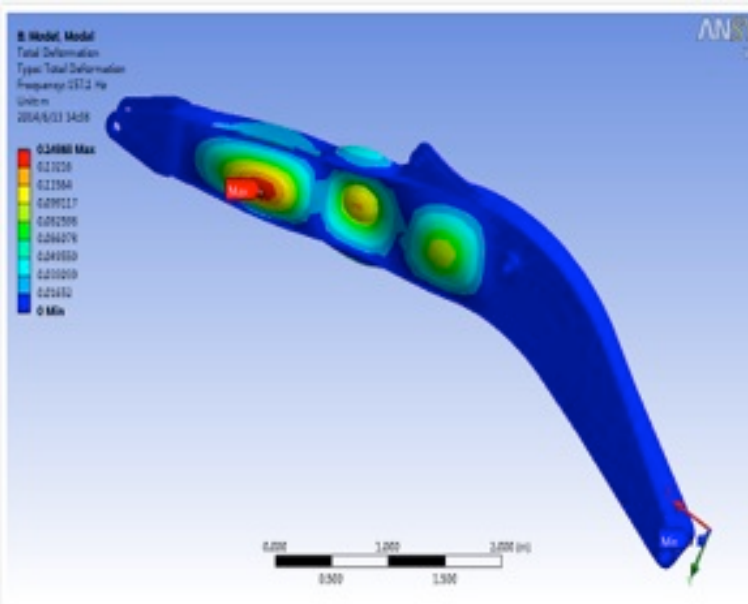

(e)

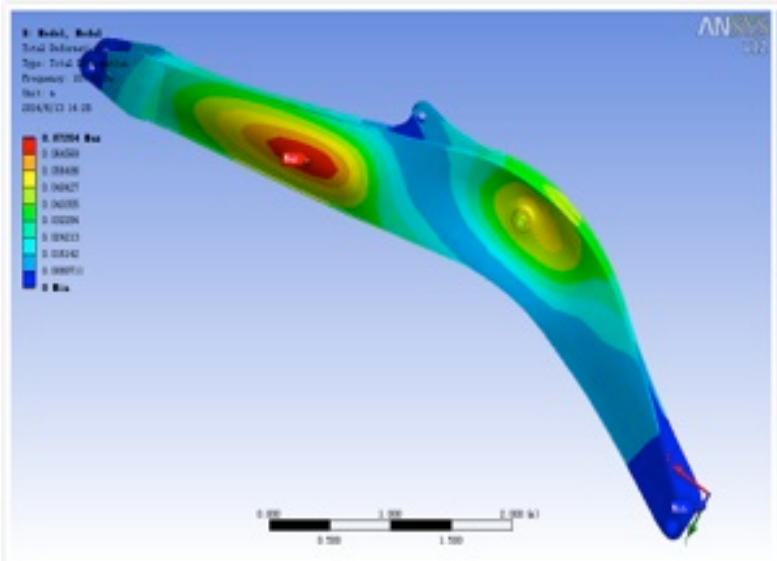

(b)

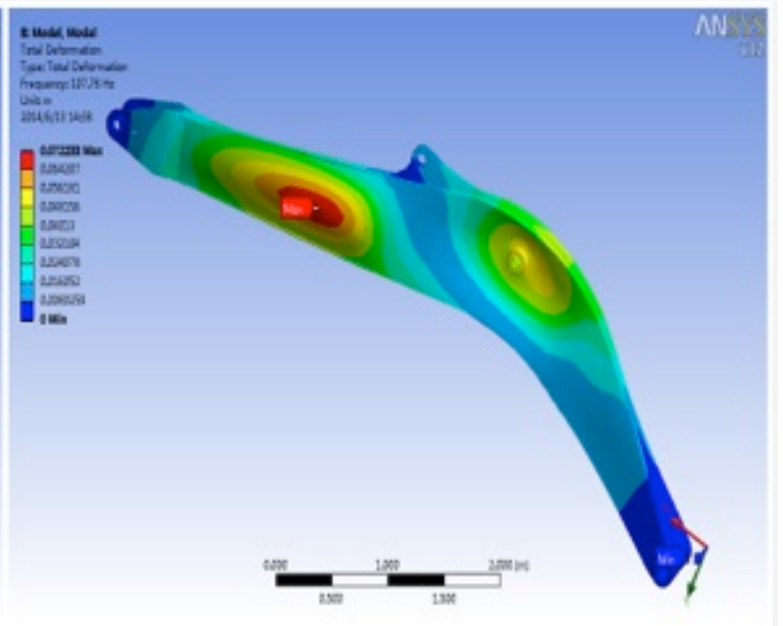

(d)

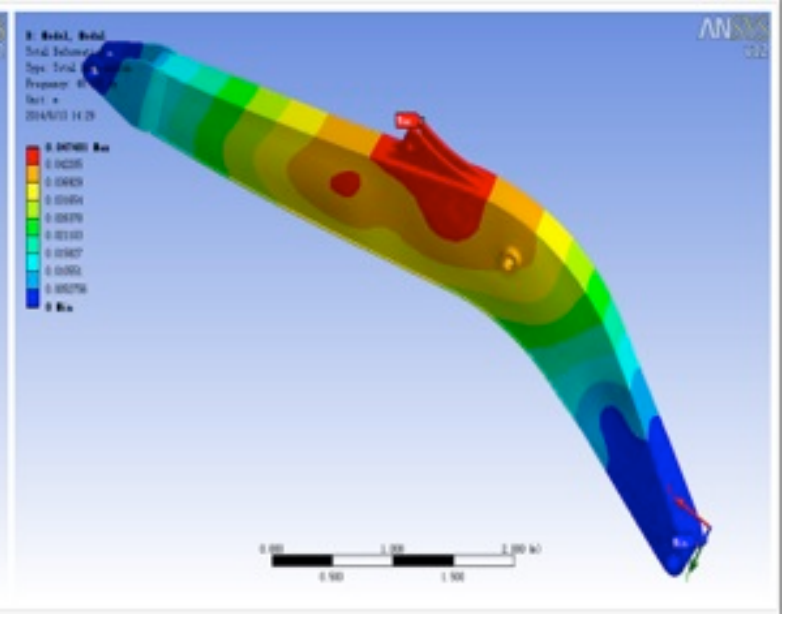

(f)

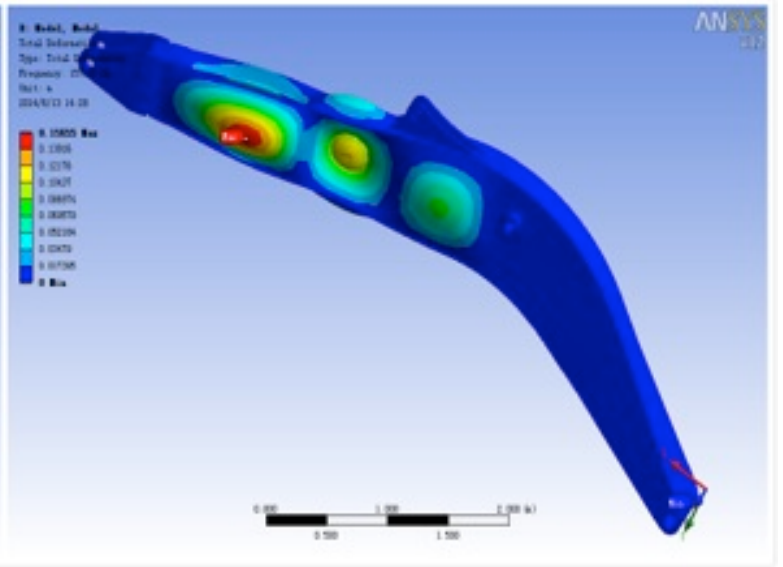

Fig. (5). Vibration modes of the boom. (a) The $1^{\text {st }}$ vibration mode under the boom condition I; (b) The $3^{\text {rd }}$ vibration mode under the boom condition I; (c) The $6^{\text {th }}$ vibration mode under the boom condition I; (d) The $1^{\text {st }}$ vibration mode under the boom condition II; (e) The $3^{\text {rd }}$ vibration mode under the boom condition II; (f) The $6^{\text {th }}$ vibration mode under the boom condition II.

attention to the maximum deformation and improve the unreasonable structure. Structure strength can be improved through welding stiffeners or by using double plates.

\section{CONFLICT OF INTEREST}

The authors declare that this article content has no conflict of interest. 
(a)

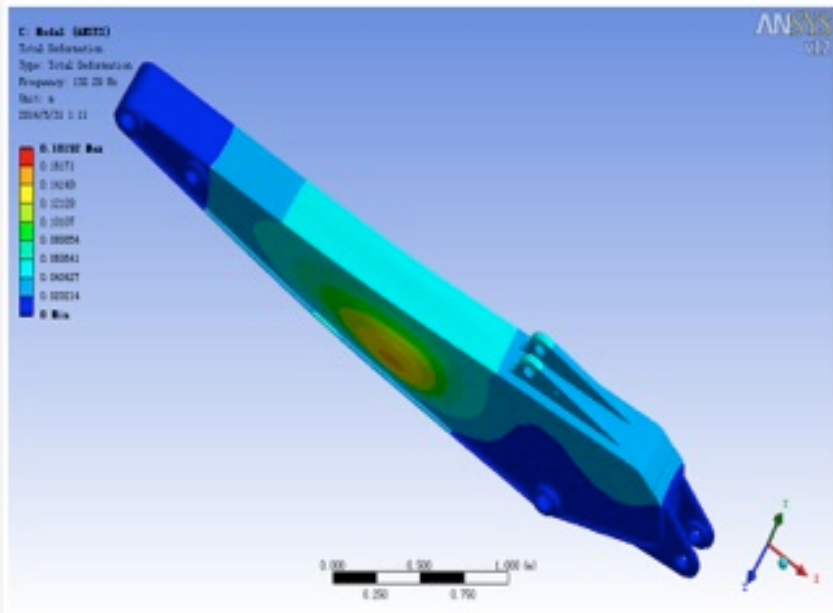

(c)

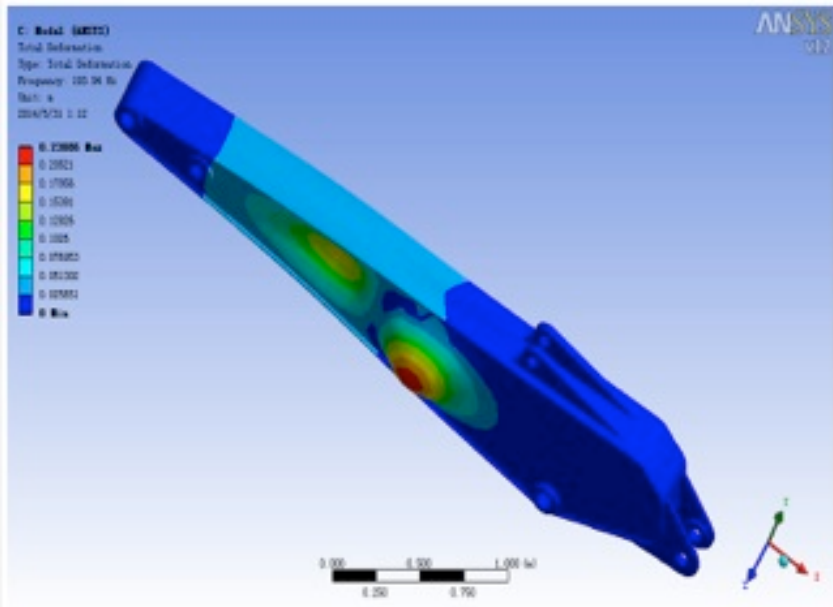

(e)

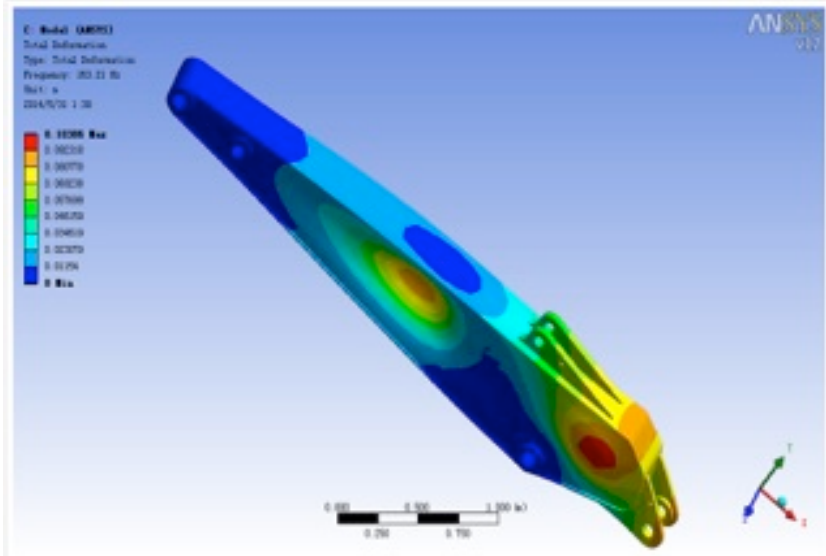

(b)

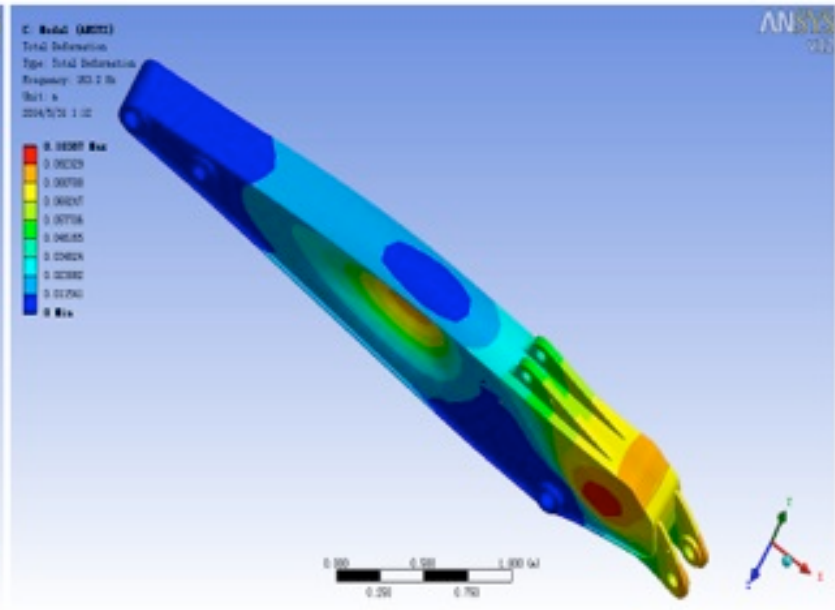

(d)

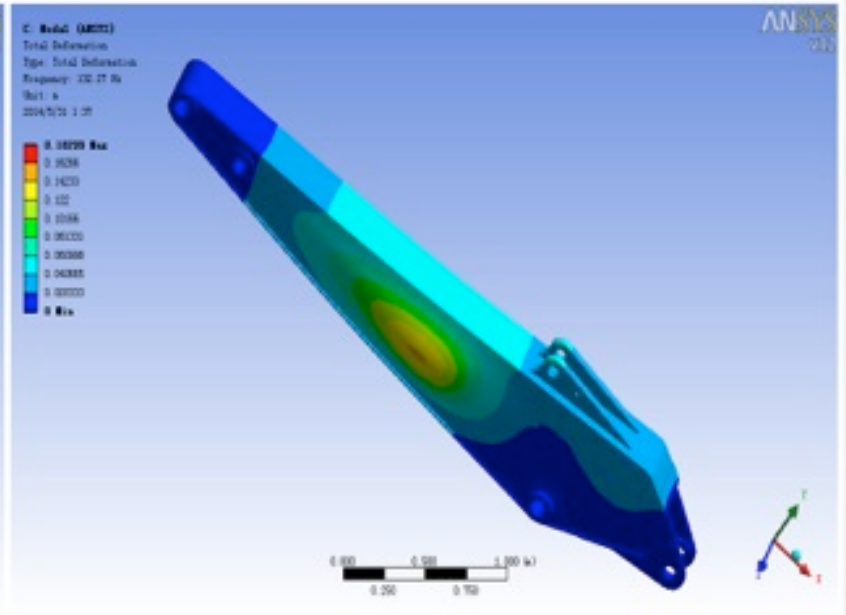

(f)

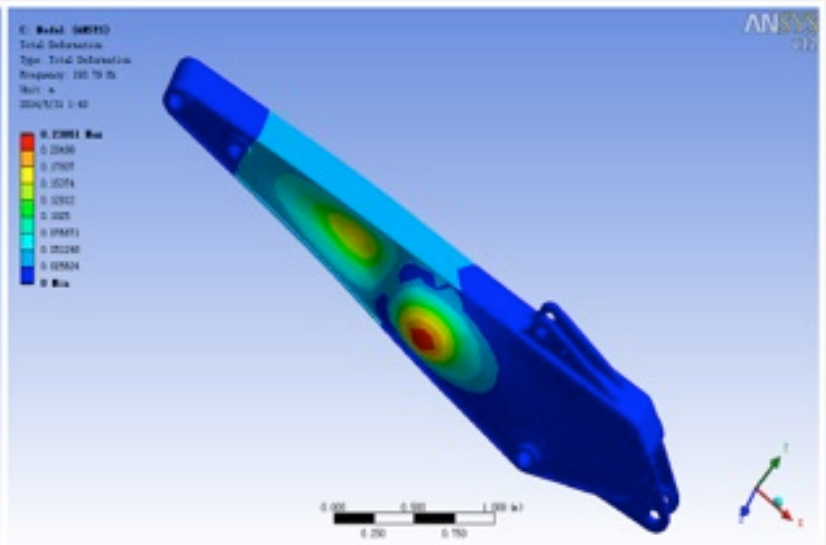

Fig. (6). The vibration modes of the bucket rod. (a) The $1^{\text {st }}$ vibration mode under the bucket rod condition I; (b) The $3^{\text {rd }}$ vibration mode under the bucket rod condition I; (c) The $6^{\text {th }}$ vibration mode under the bucket rod condition I; (d) The $1^{\text {st }}$ vibration mode under the bucket rod condition II; (e) The $3^{\text {rd }}$ vibration mode under the bucket rod condition II; (f) The $6^{\text {th }}$ vibration mode under the bucket rod condition II.

\section{ACKNOWLEDGEMENTS}

The authors would like to acknowledge Project (51274252) supported by the National Natural Science
Foundation of China and the scientific research project (12C0862) supported by the Education Department of Hunan province. 
Table 2. Bucket rod condition I and II for the first 6 orders inherent frequencies and vibration mode description.

\begin{tabular}{|c|c|c|c|}
\hline Order & $\begin{array}{l}\text { Inherent Frequency of } \\
\text { Bucket Rod Conditions } \mathbf{I} / \mathrm{Hz}\end{array}$ & $\begin{array}{l}\text { Inherent Frequency of } \\
\text { Bucket Rod Conditions II/Hz }\end{array}$ & Vibration Type Description \\
\hline 1 & 132.29 & 132.27 & $\begin{array}{c}\text { The } 1^{\text {st }} \text { order bending vibration slightly on plane } \mathrm{X}, \mathrm{Z} \text { and muster at the } \\
\text { front position of ear plate }\end{array}$ \\
\hline 2 & 136.55 & 136.37 & The muster at the front position of ear plate and no bending \\
\hline 3 & 163.20 & 163.21 & $\begin{array}{c}\text { The } 2^{\text {nd }} \text { order bending vibration on plane } \mathrm{X}, \mathrm{Z} \text { and slightly muster at } \\
\text { bending position }\end{array}$ \\
\hline 4 & 171.04 & 170.81 & $\begin{array}{l}\text { The two continuous musters at the middle position of the hinge between } \\
\text { front supporting plate and boom }\end{array}$ \\
\hline 5 & 136.48 & 185.38 & The $2^{\text {nd }}$ order bending vibration on plane $\mathrm{X}, \mathrm{Y}$ \\
\hline 6 & 193.94 & 193.79 & $\begin{array}{l}\text { The two continuous musters at the middle position of the hinge between } \\
\text { front supporting plate and boom }\end{array}$ \\
\hline
\end{tabular}

\section{REFERENCES}

[1] T. Smolnicki, D. Derlukiewicz, M. Stanco, "Evaluation of load distribution in the superstructure rotation joint of single-bucket caterpillar excavators," Automation in Construction, vol. 17, no. 3, pp. 218-223, 2008

[2] G. Wszolek, "Vibration analysis of the excavator model in GRAFSIM program on the basis of a block diagram method," Journal of Materials Processing Technology, vol. 20, no. 3, pp. 268-271, 2004.

[3] B. Liu, Finite Element Analysis on Hydraulic Excavator Backhoe Device, Xian: Chang'an University, 2003.

[4] Y. Pan, "Based on ADMAS of working equipment of excavator device simulation and design optimization," Coal Mine Machinery, vol. 30, no. 3, pp.15-17, 2009.
[5] W. Du, Research on Key Technology of Hydraulic Excavator Working Device Design, Changchun: Jilin University, 2007.

[6] R. Zhang, The Analysis of WY22 Excavator Working Device Based on ANSYS and Pro/E, Shenyang: Northeastern University, 2008.

[7] W. Tie, X. Wang, R. Yang, and Y. Zhou, "Modal analysis of excavator arm based on finite element method," Machinery Design and Manufacture, vol. 18, no. 3, pp. 23-25, 2011.

[8] F. Xue, and R. Hu, ANSYS 12.0. Mechanical and Structural Finite Element Analysis from Entry to Master, Beijing: China Machine Press, 2010

[9] J. Zhao, Design of Excavator Boom Finite Element Analysis and Optimization, Wuhan, Huazhong University of Science and Technology, 2006.

(C) Xiao and Guiju; Licensee Bentham Open.

This is an open access article licensed under the terms of the Creative Commons Attribution Non-Commercial License (http://creativecommons.org/licenses/by-nc/3.0/) which permits unrestricted, non-commercial use, distribution and reproduction in any medium, provided the work is properly cited. 